\title{
Editorial
}

\section{Carbon-Based Materials at Nanoscale}

\author{
Dan Xia, ${ }^{1}$ Michal Otyepka, ${ }^{2} \mathrm{Xi} \mathrm{Li},{ }^{3}$ Wei Liu, ${ }^{4}$ and Qingbin Zheng ${ }^{5}$ \\ ${ }^{1}$ Interdisciplinary Nanoscience Center, Aarhus University, 8000 Aarhus, Denmark \\ ${ }^{2}$ Department of Physical Chemistry, Palacký University, 77146 Olomouc, Czech Republic \\ ${ }^{3}$ Department of Environmental Science and Engineering, Fudan University, Shanghai 200433, China \\ ${ }^{4}$ School of Materials Science and Engineering, Nanjing University of Science and Technology, Nanjing 210094, China \\ ${ }^{5}$ Leibniz Institute of Polymer Research Dresden, 01005 Dresden, Germany
}

Correspondence should be addressed to Dan Xia; xiadan@inano.au.dk

Received 30 September 2015; Accepted 1 October 2015

Copyright (C) 2015 Dan Xia et al. This is an open access article distributed under the Creative Commons Attribution License, which permits unrestricted use, distribution, and reproduction in any medium, provided the original work is properly cited.

Carbon-based nanomaterials (CBNs), namely, fullerene, carbon nanotubes, and graphene, have attracted significant attention since their discoveries, and in these days they play significant role in nanoscience and nanotechnology [1]. The unique properties of CBNs make them widely used in many fields ranging within material science [2], energy [3], environment $[4,5]$, biology [6-9], medicine $[10,11]$, and so forth. Articles published in this special issue reflect the broad application potential of CBNs and provide some overview of the recent progress in this field.

The paper by M. R. Sanaee and E. Bertran is focused on iron nanoparticles encapsulated by carbon shell. The authors present a synthesis of core/shell nanostructures by using a new modified arc discharge reactor. Different iron cores including spherical, oval, and multiple cores were synthesized. The carbon shell protecting the iron cores against oxidation shows high degree of crystallinity. Due to the carbon shell spherical shape and iron superparamagnetic behavior, the authors conclude that the carbon encapsulated iron nanoparticles can be potentially used in drug delivery. X. $\mathrm{Li}$ et al. showed that magnetic carbon nanocages synthetized from a cheap carbon source material lignin using low temperature carbonization process can be used as efficient and recycled adsorbents in the removal of dye staff from textile wastewater.

The conductive polymeric composites based on multiwalled carbon nanotubes were studied by E. V. Santiago et al. By tailoring the epoxidized linseed oil matrix with groups rich in nonpolar electric density, as diacetylene, capable of interacting by van der Waals forces, it was possible to improve the dispersion of carbon nanotubes without necessity of some modification knowing that those treatments usually affect lowering their electrical properties. The authors conclude that these composites may have potential application in vapor sensors. The effect of dielectric constant of some polystyrenetype polymer matrix on the percolation threshold in conductive polymer composites with carbon black is also studied. It is confirmed that the percolation threshold decreases while the dielectric constant increases.

The hybrid materials based on CBNs are usually stabilized by noncovalent interactions with dominating van der Waals forces. The theoretical simulations of the CBNs provide useful insight into stability and nature of such interactions [12]. W. Liu et al. studied the interactions between CO molecule and the pristine and defective graphene layers using the stateof-the-art density-function theory calculations. The results clearly demonstrate that the defective graphene could be a good sensor for CO. Using theoretical calculations Q. Wu et al. showed that band gap of carbon and boron nitride doublewall heteronanotubes (C/BN-DWHNTs) with different chirality and size could be tuned by intertube distance. Imposing an external electric field of zigzag DWHNTs provides further possibility for future electronic and electrooptic nanodevice applications.

Heterogeneous catalysis belongs to extensively studied disciplines with a huge application potential in industry. The catalytic activity of nanomaterials synthetized from carbon precursor nanomaterials was studied by M.-D. Dong 
et al. The synthesized $\mathrm{Co}_{3} \mathrm{O}_{4}$ nanomaterials with different morphologies showed excellent catalytic activity for thermal decomposition of ammonium perchlorate and the $\mathrm{Co}_{3} \mathrm{O}_{4}$ nanorods with large BET surface area and pore volume had the highest catalytic activity. Organic solar cells are also extensively studied materials because they can be applied as sustainable source of energy. A. Manzano-Ramírez et al. reviewed the efficiency of graphene-based bulk heterojunction $(\mathrm{BHJ})$ organic solar cells. The various applications of graphene as a constituent of $\mathrm{BHJ}$ organic solar cells were discussed focusing on the PCE achieved by the graphene based devices.

Radio frequency magnetron sputtering was used for deposition of hydrogenated amorphous carbon films codoped with $\mathrm{Si}$ and $\mathrm{Al}((\mathrm{Si}, \mathrm{Al}) / \mathrm{a}-\mathrm{C}: \mathrm{H})$ on $\mathrm{Si}(100)$ substrate at different temperatures. The substrate temperature effect on microstructure, mechanical, and tribological properties of the $(\mathrm{Si}, \mathrm{Al}) / \mathrm{a}-\mathrm{C}: \mathrm{H}$ films was studied and the correlation between the structure, mechanical, and tribological properties was also discussed by X. Liu et al.

We are confident that this special issue will provide new insights and inspiration to the interested reader for further work in the field of CBNs. Many individuals contributed to the success of this special issue.

\section{Acknowledgments}

We would like to thank all authors who submitted their papers for publication in this special issue. We would also like to acknowledge the referees who have put in the hard work and their valuable time to review each paper in a timely and professional way.

Dan Xia
Michal Otyepka
Xi Li
Wei Liu
Qingbin Zheng

\section{References}

[1] V. Georgakilas, J. A. Perman, J. Tucek, and R. Zboril, "Broad family of carbon nanoallotropes: classification, chemistry, and applications of fullerenes, carbon dots, nanotubes, graphene, nanodiamonds, and combined superstructures," Chemical Reviews, vol. 115, no. 11, pp. 4744-4822, 2015.

[2] Q. Li, J. Song, F. Besenbacher, and M. Dong, "Two-dimensional material confined water," Accounts of Chemical Research, vol. 48, no. 1, pp. 119-127, 2015.

[3] D. Yu, K. Goh, H. Wang et al., "Scalable synthesis of hierarchically structured carbon nanotube-graphene fibres for capacitive energy storage," Nature Nanotechnology, vol. 9, no. 7, pp. 555$562,2014$.

[4] Q. Xue, H. Chen, Q. Li, K. Yan, F. Besenbacher, and M. Dong, "Room-temperature high-sensitivity detection of ammonia gas using the capacitance of carbon/silicon heterojunctions," Energy \& Environmental Science, vol. 3, no. 3, pp. 288-291, 2010.

[5] H. Sun, X. You, J. Deng et al., "Novel graphene/carbon nanotube composite fibers for efficient wire-shaped miniature energy devices," Advanced Materials, vol. 26, no. 18, pp. 2868-2873, 2014.

[6] C. Ge, J. Du, L. Zhao et al., "Binding of blood proteins to carbon nanotubes reduces cytotoxicity," Proceedings of the National Academy of Sciences of the United States of America, vol. 108, no. 41, pp. 16968-16973, 2011.

[7] X. Zhang, W. Hu, J. Li, L. Tao, and Y. Wei, "A comparative study of cellular uptake and cytotoxicity of multi-walled carbon nanotubes, graphene oxide, and nanodiamond," Toxicology Research, vol. 1, no. 1, pp. 62-68, 2012.

[8] M. V. Khodakovskaya, K. de Silva, A. S. Biris, E. Dervishi, and H. Villagarcia, "Carbon nanotubes induce growth enhancement of tobacco cells," ACS Nano, vol. 6, no. 3, pp. 2128-2135, 2012.

[9] Y. Liu, X. Dong, and P. Chen, "Biological and chemical sensors based on graphene materials," Chemical Society Reviews, vol. 41, no. 6, pp. 2283-2307, 2012.

[10] M. Adeli, R. Soleyman, Z. Beiranvand, and F. Madani, "Carbon nanotubes in cancer therapy: a more precise look at the role of carbon nanotube-polymer interactions," Chemical Society Reviews, vol. 42, no. 12, pp. 5231-5256, 2013.

[11] M. Zheng, S. Liu, J. Li et al., "Integrating oxaliplatin with highly luminescent carbon dots: an unprecedented theranostic agent for personalized medicine," Advanced Materials, vol. 26, no. 21, pp. 3554-3560, 2014.

[12] M. Pykal, P. Jurečka, F. Karlický, and M. Otyepka, "Modelling of graphene functionalization," Physical Chemistry Chemical Physics, 2015. 

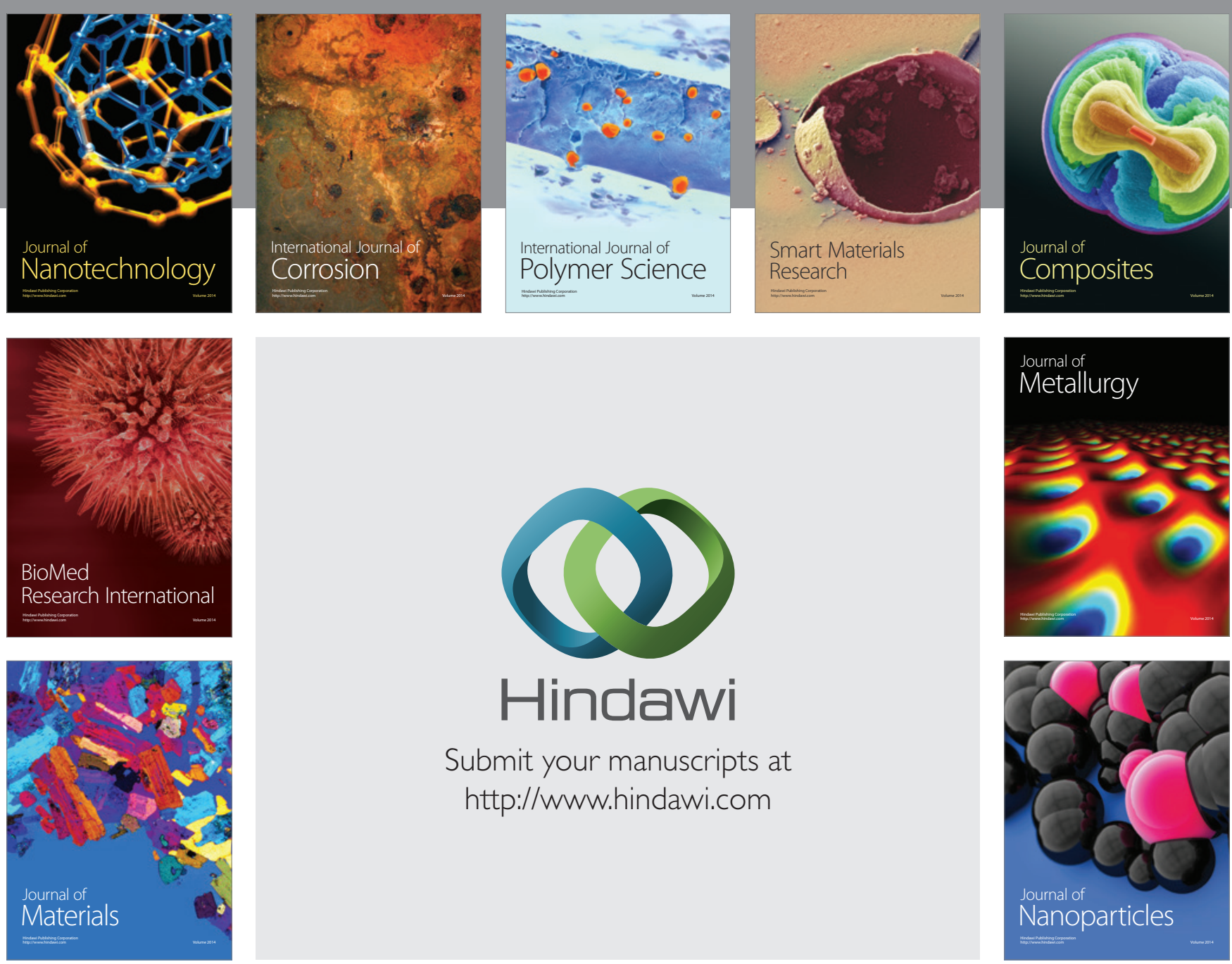

Submit your manuscripts at http://www.hindawi.com
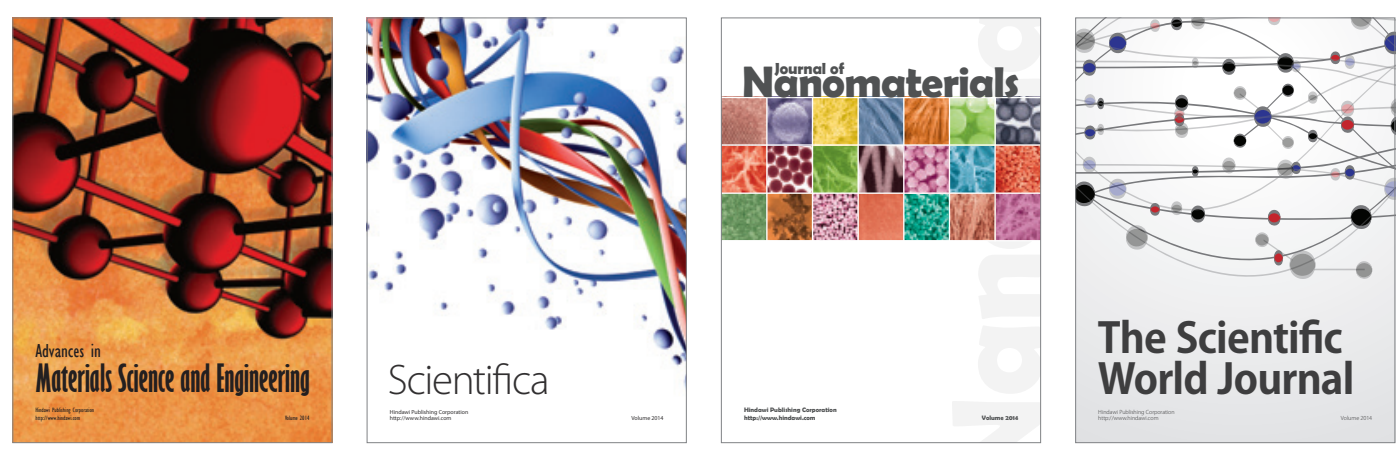

\section{The Scientific World Journal}
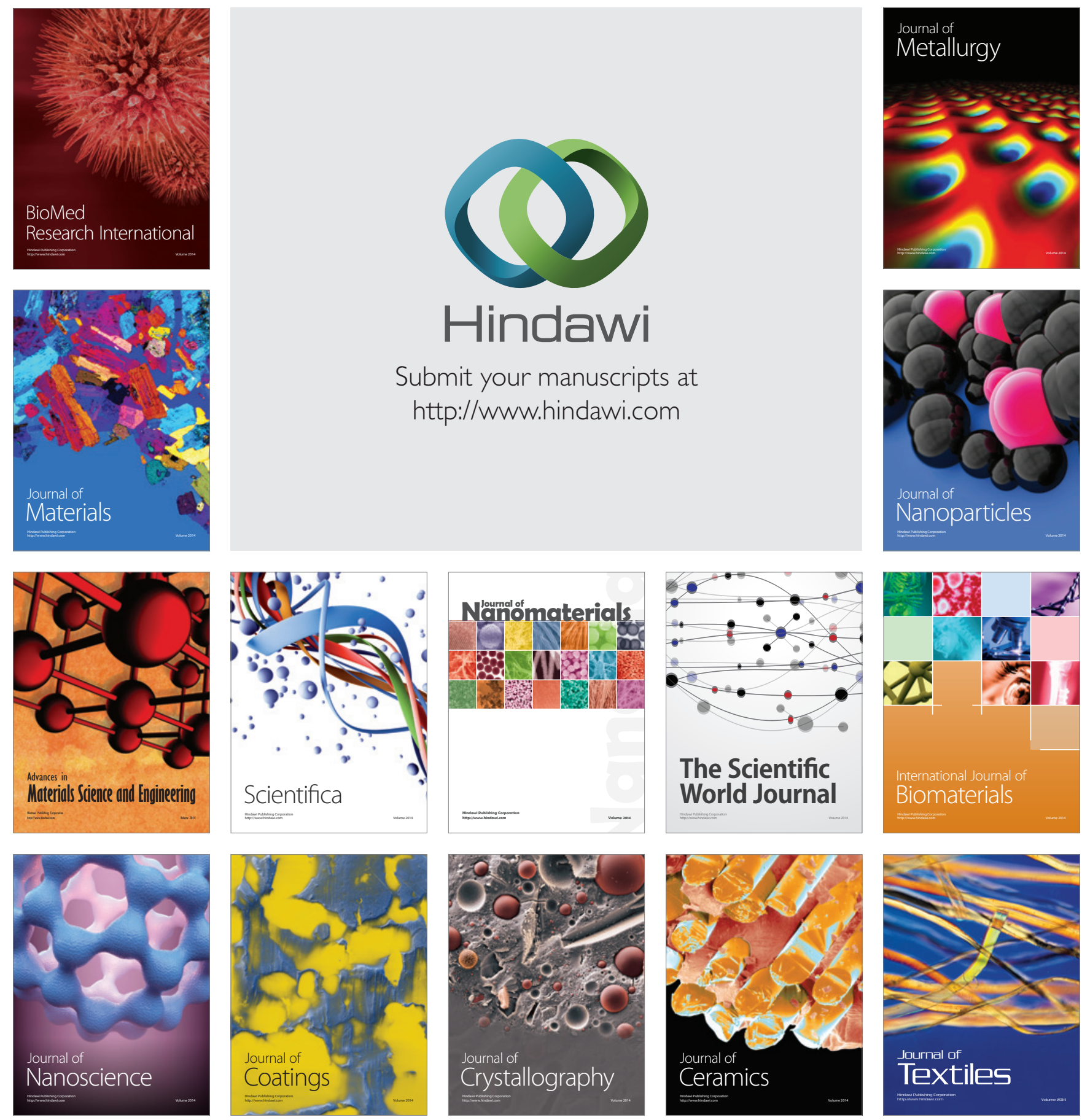